\title{
microRNA in situ hybridization for miR-211 detection as an ancillary test in melanoma diagnosis
}

\author{
Sankhiros Babapoor ${ }^{1,6}$, Michael Horwich ${ }^{2,6}$, Rong $\mathrm{Wu}^{3}$, Shauna Levinson ${ }^{4}$, Manoj Gandhi ${ }^{4}$, \\ Hanspaul Makkar², Arni Kristjansson², Mary Chang ${ }^{2}$ and Soheil S Dadras ${ }^{1,2,5}$ \\ ${ }^{1}$ Department of Genetics and Genomic Sciences, University of Connecticut Health Center, Farmington, CT, \\ USA; ${ }^{2}$ Department of Dermatology, University of Connecticut Health Center, Farmington, CT, USA; \\ ${ }^{3}$ Connecticut Institute for Clinical and Translational Science Biostatics Center, University of Connecticut \\ Health Center, Farmington, CT, USA ${ }^{4}$ Affymetrix, Santa Clara, CA, USA and ${ }^{5}$ Department of Anatomic \\ Pathology, University of Connecticut Health Center, Farmington, CT, USA
}

\begin{abstract}
Some melanocytic tumors can be histologically ambiguous causing diagnostic difficulty, which could lead to overtreatment of benign lesions with an unwarranted psychological distress or undertreatment of malignant cancers. Previously, we demonstrated that significantly decreased miR-211 expression in melanomas compared with melanocytic nevi could accurately discriminate malignant from benign tumors. Herein we show microRNA in situ hybridization for fluorescent detection of miR-211, suitable for paraffin-embedded tissues in 109 primary melanocytic tumors. miR-211 expression was significantly lower in melanomas vs nevi $(P<0.0001)$, and receiver operating characteristic curve (area under the curve $=0.862$ ) accurately discriminated melanomas from nevi with $90 \%$ sensitivity and $86.2 \%$ specificity. Qualitatively, all dysplastic nevi expressed miR-211 at high (86\%) and low (14\%) levels, independent of the degree of nuclear atypia. All 35 melanocytic tumors with Spitz morphology expressed miR-211 independent of morphological classification, where clinical follow-up of these patients showed no recurrence at the site or metastasis in mean and median of 3 (ranging 2-5) years. Moreover, a decision tree learning analysis selected age and miR-211 miRNA in situ hybridization as the predictive variables for benign or malignant outcome in 88 patients correctly classified $92 \%$ ( 81 out of 88 ) of cases as proven by receiver operating characteristic curve (area under the curve $=0.9029$ ). These results support miR-211 as a leading miRNA candidate for melanoma diagnosis and miRNA in situ hybridization as a uniquely uncomplicated ancillary test.

Modern Pathology (2016) 29, 461-475; doi:10.1038/modpathol.2016.44; published online 26 February 2016
\end{abstract}

\section{Introduction}

The incidence and mortality of melanoma have continually increased over the past decades in the United States. It is estimated that 76250 individuals (44 250 men and 32000 women) will be diagnosed with and 9180 men and women will die of melanoma of the skin in $2012 .{ }^{1}$ Increasing incidence is coupled by diagnostic discrepancies ${ }^{2}$ whereby a small but significant number of clinically

Correspondence: Dr SS Dadras, MD, PhD, Department of Dermatology, University of Connecticut Health Center, 21 South Road, Farmington, CT 06032, USA.

E-mail: dadras@uchc.edu

${ }^{6}$ These authors contributed equally to this work.

Received 21 October 2015; revised 22 January 2016; accepted 23

January 2016; published online 26 February 2016 suspicious pigmented lesions may show ambiguous histopathology making the classification between benign (common nevus) and malignant (melanoma) melanocytic tumors difficult and the clinical behavior unpredictable. ${ }^{3}$ Notwithstanding the distinct sets of genetic alterations demonstrated in melanoma by array-based comparative genomic hybridization $^{4}$ and by DNA-based fluorescence in situ hybridization, ${ }^{5}$ the changes in non-coding RNA (part of the genome that does not encode genes) during melanoma progression and how they could be exploited in diagnostic pathology remain uncharacterized.

microRNAs (miRNAs) are endogenous $\sim 22$ nucleotide non-coding small RNAs, negative regulators of gene expression, whose levels are significantly changed in a growing number cancers, eg, breast (ductal carcinoma in situ and invasive), colorectal 
Table 1 Clinical characteristics of patients with melanocytic tumors

\begin{tabular}{|c|c|c|c|c|c|c|}
\hline & Common nevus & Dysplastic nevus & $\begin{array}{l}\text { Primary cutaneous } \\
\text { melanoma }\end{array}$ & Spitz nevus & $\begin{array}{l}\text { Atypical Spitz } \\
\text { tumor }\end{array}$ & $\begin{array}{l}\text { Spitzoid } \\
\text { melanoma }\end{array}$ \\
\hline Age, mean (years) & 40.1 & 46.4 & 62.7 & 5.7 & 22.6 & 32.9 \\
\hline Age range (years) & $11-68$ & $32-71$ & $32-93$ & $1-11$ & $4-63$ & $2-72$ \\
\hline \multicolumn{7}{|l|}{ Gender } \\
\hline Male & 15 & 11 & 9 & 5 & 4 & 3 \\
\hline Female & 17 & 10 & 12 & 6 & 13 & 4 \\
\hline \multicolumn{7}{|l|}{ Anatomic site } \\
\hline Head and neck & 9 & 1 & 2 & 4 & 2 & 3 \\
\hline Upper extremity & 4 & 0 & 7 & 1 & 4 & 0 \\
\hline Trunk & 18 & 18 & 7 & 2 & 2 & 1 \\
\hline Lower extremity & 1 & 2 & 3 & 3 & 5 & 3 \\
\hline Glabrous skin & 0 & 0 & 2 & 1 & 4 & 0 \\
\hline Total & 32 & 21 & 21 & 11 & 17 & 7 \\
\hline
\end{tabular}

carcinoma, malignant melanoma and papillary thyroid carcinoma. The changes in specific miRNAs have been shown to be associated with cancer diagnosis or outcome, which can be readily detected by quantitative real-time reverse transcriptase PCR (qRT-PCR) in formalin-fixed paraffin-embedded specimens. In fact, it has been shown that specific miRNAs function as tumor suppressors and oncogenes in human malignancies; ${ }^{6-8}$ however, their tissue-specific expression patterns remain understudied by miRNA in situ hybridization in diagnostic material.

Measuring the levels of specific miRNAs by array-based profiling strategies can classify human cancers. ${ }^{9}$ Using next-generation sequencing of miRNA transcriptome and validated by qRT-PCR in biopsies of common nevi, thick primary $(>4.0 \mathrm{~mm})$ and metastatic melanomas, we defined a set of top 40 miRNAs, which correctly classified melanomas from nevi in archived specimens. ${ }^{10}$ Among the top miRNAs, miR-211 expression was significantly decreased in melanomas compared with melanocytic nevi, which was confirmed in an independent validation cohort of 101 specimens by qRT-PCR. ${ }^{10}$ Moreover, the receiver operating characteristic curves for miR-211 expression accurately discriminated invasive melanoma (area under the receiver operating characteristic curve $(\mathrm{AUC})=0.933)$, melanoma in situ (AUC=0.933) and dysplastic (atypical) nevi (AUC $=0.951$ ) from common nevi. ${ }^{10}$ Corroborating our findings in clinical specimens, others and we have shown that miR-211 functions as a potent tumor suppressor in vitro influencing gene pathways involved in cell invasion. ${ }^{11-13}$ Notably, miR-211 is located within the non-coding sequence (intron 6) of Melastatin-1 (MLSN-1) gene, ${ }^{11}$ which is expressed at high levels in melanocytic nevi but significantly reduced in metastatic human melanomas with variable expression in primary lesions. ${ }^{14}$ Loss of MLSN-1 mRNA is predictive of significantly reduced disease-free survival in a study of 150 melanoma patients. ${ }^{15}$ These results strongly suggest that miR-211 might be associated with a malignant behavior in melanoma.

As we had previously demonstrated that significantly decreased miR-211 expression could discriminate malignant from benign in 129 histologically unambiguous melanocytic tumors, we investigated whether miRNA in situ hybridization could be applied to aid in the diagnosis of ambiguous lesions. We confirmed that miR-211 expression was decreased in melanomas compared with nevi by fluorescent and chromogenic miRNA in situ hybridization. Moreover, our present data support the diagnostic utility of miR-211 in dysplastic nevi and melanocytic tumors with Spitz morphology.

\section{Materials and methods}

\section{Study Population and Clinical Samples}

Formalin-fixed paraffin-embedded sections from common melanocytic nevi, dysplastic nevi, primary cutaneous melanomas, Spitz nevi, atypical Spitz tumors and spitzoid melanomas were obtained from the archives of Department of Dermatology at University of Connecticut Health Center between 2009 and 2013 (Table 1). In addition, we purchased melanoma tissue microarrays, T385a and T388 from US Biomax (Rockville, MD, USA) consisting of 24 tissue cores in duplicates or triplicates. For the melanomas, 11 cases were full sections and 10 were from tissue microarrays. For each specimen, a hematoxylin-eosin-stained section was used for histopathological evaluation, diagnostic confirmation, pathological staging and imaging. In total, we examined 109 individual lesions for the study (Table 1).

The inclusion criteria for diagnostic groups were as follows. The common melanocytic nevi were either junctional or combined with proper 
Table 2 Summary of fluorescent miR-211 intensity for each diagnostic group

\begin{tabular}{|c|c|c|c|c|c|c|c|}
\hline Diagnostic group & $\mathrm{n}$ & miR-211 intensity, mean \pm s.d. & Median & Min & $\operatorname{Max}$ & Interquartile range & P-value \\
\hline Common nevus & 32 & $60.7 \pm 18.0$ & 61.1 & 17.5 & 111.9 & 17.7 & $<0.0001^{\mathrm{a}}$ \\
\hline Primary cutaneous melanoma & 21 & $31.7 \pm 20.4$ & 30.1 & 8.8 & 90.8 & 12.2 & \\
\hline Spitz nevus & 11 & $51.4 \pm 27.2$ & 41.0 & 20.2 & 100.3 & 29.5 & 0.4373 \\
\hline Atypical Spitz tumor & 17 & $42.2 \pm 15.1$ & 44.3 & 11.1 & 62.5 & 25.5 & \\
\hline Spitzoid melanoma & 7 & $51.8 \pm 16.2$ & 57.8 & 22.7 & 70.7 & 21.0 & \\
\hline
\end{tabular}

${ }^{\mathrm{a}}$ The difference between two diagnostic groups was assessed using two-group $t$-test and non-parametric alternative (Mann-Whitney test) and the results were consistent.

Table 3 Clinicopathological correlation between average semiquantitative miR-211 intensity and cytological atypia in dysplastic nevi

\begin{tabular}{|c|c|c|c|c|c|c|c|}
\hline Case no. & Diagnostic group & Ave. miR-211 Intensity & miR-211 score & Age & Sex & Location & Cytological atypia \\
\hline 1 & Dysplastic nevus & 1.5 & High & 50 & $\mathrm{~F}$ & Shin, superior & Mild \\
\hline 2 & Dysplastic nevus & 2.0 & High & 50 & $\mathrm{~F}$ & Shin, inferior & Moderate \\
\hline 3 & Dysplastic nevus & 2.8 & High & 50 & $\mathrm{~F}$ & Left clavicle & Mild \\
\hline 4 & Dysplastic nevus & 2.8 & High & 50 & $\mathrm{~F}$ & Right shoulder & Mild \\
\hline 5 & Dysplastic nevus & 1.8 & High & 39 & $\mathrm{M}$ & Upper back & Mild \\
\hline 6 & Dysplastic nevus & 1.8 & High & 39 & $\mathrm{M}$ & Mid-back & Moderate \\
\hline 7 & Dysplastic nevus & 2.0 & High & 39 & $\mathrm{M}$ & Lateral mid-back & Moderate \\
\hline 8 & Dysplastic nevus & 0.5 & Low & 39 & $\mathrm{M}$ & Left mid-back & Moderate \\
\hline 9 & Dysplastic nevus & 2.5 & High & 39 & $\mathrm{M}$ & Chest & Moderate \\
\hline 10 & Dysplastic nevus & 2.0 & High & 41 & $\mathrm{M}$ & Upper back, superior & Moderate \\
\hline 11 & Dysplastic nevus & 1.8 & High & 41 & $\mathrm{M}$ & Upper back, inferior & Moderate \\
\hline 12 & Dysplastic nevus & 2.0 & High & 41 & $\mathrm{M}$ & Lower back & Mild \\
\hline 13 & Dysplastic nevus & 2.0 & High & 71 & $\mathrm{M}$ & Lower back & Moderate \\
\hline 14 & Dysplastic nevus & 2.8 & High & 48 & $\mathrm{~F}$ & Mid back & Moderate \\
\hline 15 & Dysplastic nevus & 1.0 & Low & 48 & $\mathrm{~F}$ & Lateral mid-back & Mild \\
\hline 16 & Dysplastic nevus & 2.3 & High & 32 & $\mathrm{~F}$ & Upper back & Moderate \\
\hline 17 & Dysplastic nevus & 1.3 & Low & 69 & $\mathrm{M}$ & Abdomen & Moderate \\
\hline 18 & Dysplastic nevus & 2.5 & High & 24 & $\mathrm{~F}$ & Abdomen & Moderate \\
\hline 19 & Dysplastic nevus & 2.5 & High & 79 & $\mathrm{M}$ & Right lower back & Moderate \\
\hline 20 & Dysplastic nevus & 3.0 & High & 26 & $\mathrm{~F}$ & Left inferior frontal scalp & Severe \\
\hline 21 & Dysplastic nevus & 2.0 & High & 60 & $\mathrm{~F}$ & Back & Moderate \\
\hline Mean & & $2.0 \pm 0.6$ & & & & & \\
\hline
\end{tabular}

maturation of melanocytes (cells become smaller and more spindled) with increasing dermal depth. The primary cutaneous melanomas were predominately superficial spreading or nodular subtypes. The Spitz nevi were characterized by well-defined, symmetric silhouette, melanocyte maturation by increasing dermal depth, epithelioid and spindled cells and lack of any dermal mitoses as determined by several additional deeper sections. Atypical Spitz tumor group was characterized by asymmetric silhouette, focal pagetoid scatter, focal lack of proper maturation or a single dermal mitotic figure. In addition, the cytology showed epithelioid and spindled cells with slight atypia and conspicuous nucleoli. The spitzoid melanoma were predominately invasive (two cases were in situ) exhibiting asymmetric silhouette, pagetoid scatter, lack of proper maturation, epithelioid and spindled cells and/or dermal mitotic figure(s). The cytopathology showed significant atypia with vesicular chromatin and macronucleoli. Lesions with Spitz morphology were additionally reviewed in a consensus conference seen at least by three pathologists and sent to an expert dermatopathologist for a second opinion. For the study, at least two board-certified pathologists/ deramtopathologists confirmed all rendered diagnoses. The institutional review board of the University of Connecticut Health Center approved this protocol.

\section{Fluorescent miRNA In Situ Hybridization}

Formalin-fixed paraffin-embedded sections were cut at $5-\mu \mathrm{m}$ thick, mounted on positively charged slides (Fisher Scientific, Pittsburgh, PA, USA). miRNA in situ hybridization was performed as described ${ }^{16}$ with slight modifications. Briefly, tissue sections were baked at $60^{\circ} \mathrm{C}$ for $20 \mathrm{~min}$ and deparaffinized in three exchanges of xylene and rehydrated in an ethanol gradient. Then the slides were treated with $20 \mu \mathrm{g} / \mathrm{ml}$ proteinase $\mathrm{K}$ (Ambion, USA) for $10 \mathrm{~min}$ at $37^{\circ} \mathrm{C}$ and fixed in $4 \%$ paraformaldehyde (Thermo Scientific, Rockford, IL, USA). Then, slides were rinsed in $0.13 \mathrm{M}$ 1-methylimidazole (Sigma-Aldrich, St Louis, MO, USA) followed by an additional fixation with 0.16 M 1-ethyl-3-(3-dimethylaminopropyl) 
carbodiimide (EDC, Sigma-Aldrich). Endogenous peroxidases were blocked in 1\% hydrogen peroxide (Sigma-Aldrich). Slides were prehybridized at $50{ }^{\circ} \mathrm{C}$ in hybridization buffer followed by hybridization in $80 \mathrm{nM}$ double Digoxigenin-labeled LNA-modified probe corresponding to mature miR-211 (sequence: 5'-AGGCGAAGGATGACAAAGGGAA-3'), a scrambled probe (sequence: 5'-GTGTAACACGTCTATACGCCC A-3') and $5^{\prime}$ Digoxigenin-labeled U6 probe (sequence: 5'-CACGAATTTGCGTGTCATCCTT-3') (Exiqon, Copenhagen, Denmark) for $1 \mathrm{~h}$ at $50^{\circ} \mathrm{C}$. Slides were washed thrice in $2 \times$ SSC, with the first wash at hybridization temperature and subsequent washes at room temperature, blocked in $0.5 \%$ Roche blocking reagent (Roche Diagnostics, Indianapolis, IN, USA) and then incubated in 1:100 Anti- Digoxigenin-HRP antibody (Novus Biologicals, CO, USA) for $1 \mathrm{~h}$ at room temperature. Slides were then washed twice in $0.1 \%$ Tween-20 PBS (PBS-T) and once in PBS, then incubated in 1:50 TSA Cyanine 3 reagent (Perkin Elmer, Norwalk, CT, USA) for $30 \mathrm{~min}$ and washed again as above. Nuclei were counterstained with DRAQ5 (Cell Signaling Technology, MA, USA) and then the slides were mounted using Prolong Gold (Invitrogen, CA, USA) mounting medium.

\section{Fluorescent Microscopy and Measurement of Fluorescent Intensity}

Images were acquired with a Zeiss LSM ConfoCor3 confocal microscope (Carl Zeiss, Germany) and EVOS FL Auto Cell Imaging System (Advanced Microscopy Group, Life Technologies, NY, USA), under constant exposure time and gain for all specimens, including positive (U6) and negative (scramble miRNA) controls. We captured $\times 20$ images in multiple regions, consisting of 3-5 fields per lesion. Then using multi-position imaging and MetaMorph microscopy automation and image analysis software (Sunnyvale, CA, USA), we measured the signal intensity per $\times 20$ image fields. The results were averaged and reported as miRNA in situ hybridization intensity for each case. The mean, median, minimum, maximum and interquartile range were calculated (Tables 2 and 4). The fluorescent expression of miR-211 was examined in the normal skin, which was expressed in the nuclei and cytoplasm of most epidermal keratinocytes. A semiquantitative, four-point ordinal reactivity score was established for dysplastic nevi: ' 0 ' reflected the lack of miR-211 and was the most common pattern in invasive and in situ melanomas in $<10 \%$ of tumor cells. Weakly positive expression was designated as ' 1 ' if expression was detected in 10-30\%; moderately positive ' 2 ' in $31-60 \%$ and strongly positive ' 3 ' in $>61 \%$ of tumor cells. Only staining of tumor cells was scored in comparison to adjacent keratinocytes (internal positive control). Two investigators scored the slides independently. Scores for multiple cores from one case were averaged, and final miR-211 scores were categorized into a three-level grouping of Negative, Low ( $>0$ and $\leq 1.4)$ or High $(>1.5)$.

\section{Chromogenic miRNA In Situ Hybridization}

Two melanocytic nevi and two primary cutaneous melanomas with unambiguous histopathology were selected. Bacillus subtilis dihdrodipicolinate reductase $(D a p B)$ gene and let-7a, a highly abundant human miRNA, were used as negative and positive controls, respectively. Custom designed probes for miR-211, DapB and let7a were synthesized. Hybridization was performed using a modified protocol of the ViewRNA in situ hybridization tissue protocol (Affymetrix, Santa Clara, CA, USA). Thirty formalin-fixed paraffin-embedded sections were cut at $5-\mu \mathrm{m}$ thickness for each case (two additional nevi and melanomas) and mounted on positively charged SurgiPath X-tra slides (Leica Biosystems, Buffalo Grove, IL, USA). Tissue sections were baked at $60^{\circ} \mathrm{C}$ for $60 \mathrm{~min}$, deparaffinized using xylene followed by ethanol dehydration and air-dried. Slides were rehydrated in $1 \times$ PBS followed by protease digestion (1:150 dilution, Affymetrix) for $30 \mathrm{~min}$ at $37^{\circ} \mathrm{C}$ and fixed in $4 \%$ formaldehyde for $5 \mathrm{~min}$ at RT. Slides were rinsed in $1 \times$ PBS followed by hybridization with $12.5 \mathrm{~nm}$ final concentration of miRNA in situ hybridization probe for $2 \mathrm{~h}$ at $40^{\circ} \mathrm{C}$. Signal amplification was achieved using the branched DNA technology with a series of sequential hybridization and washes. Briefly, posthybridized slides were hybridized with the preamplifier mix for $25 \mathrm{~min}$ at $40^{\circ} \mathrm{C}$, followed by amplifier mix for $15 \mathrm{~min}$ at $40^{\circ} \mathrm{C}, \quad 1: 1000$ dilution of Alkaline-Phosphatase (AP)-labeled probe for $15 \mathrm{~min}$ at $40^{\circ} \mathrm{C}$ and $\mathrm{AP}$ enhancer for $5 \mathrm{~min}$ at $\mathrm{RT}$. The chromogenic reaction was carried out incubating Fast Red Substrate for $30 \mathrm{~min}$ at $40^{\circ} \mathrm{C}$. Slides were postfixed with $4 \%$ formaldehyde for $5 \mathrm{~min}$ at RT, counterstained with Gill's Hematoxylin and mounted using Advantage (Innovex Biosciences, Richmond, CA, USA) mounting media. Overall, the measured red dots (miRNA signal) for $D a p B$ was hardly detected (1 dot/10 cells) and for let-7a abundantly present ( $>10$ dots/cell) in the cases tested.

\section{Statistical Analysis}

The statistical analyses were performed using SAS version 9.3. Difference between two diagnostic groups was assessed using two independent sample $t$-test or non-parametric alternative (Mann-Whitney test). Difference between more than two diagnostic groups was assessed using Kruskal-Wallis Test. A $P$-value $<0.05$ was considered statistically significant in analysis. To evaluate how miR-211 expression distinguishes melanoma from nevus, we used different cutoff values of miRNA in situ hybridization intensity to calculate sensitivity and 

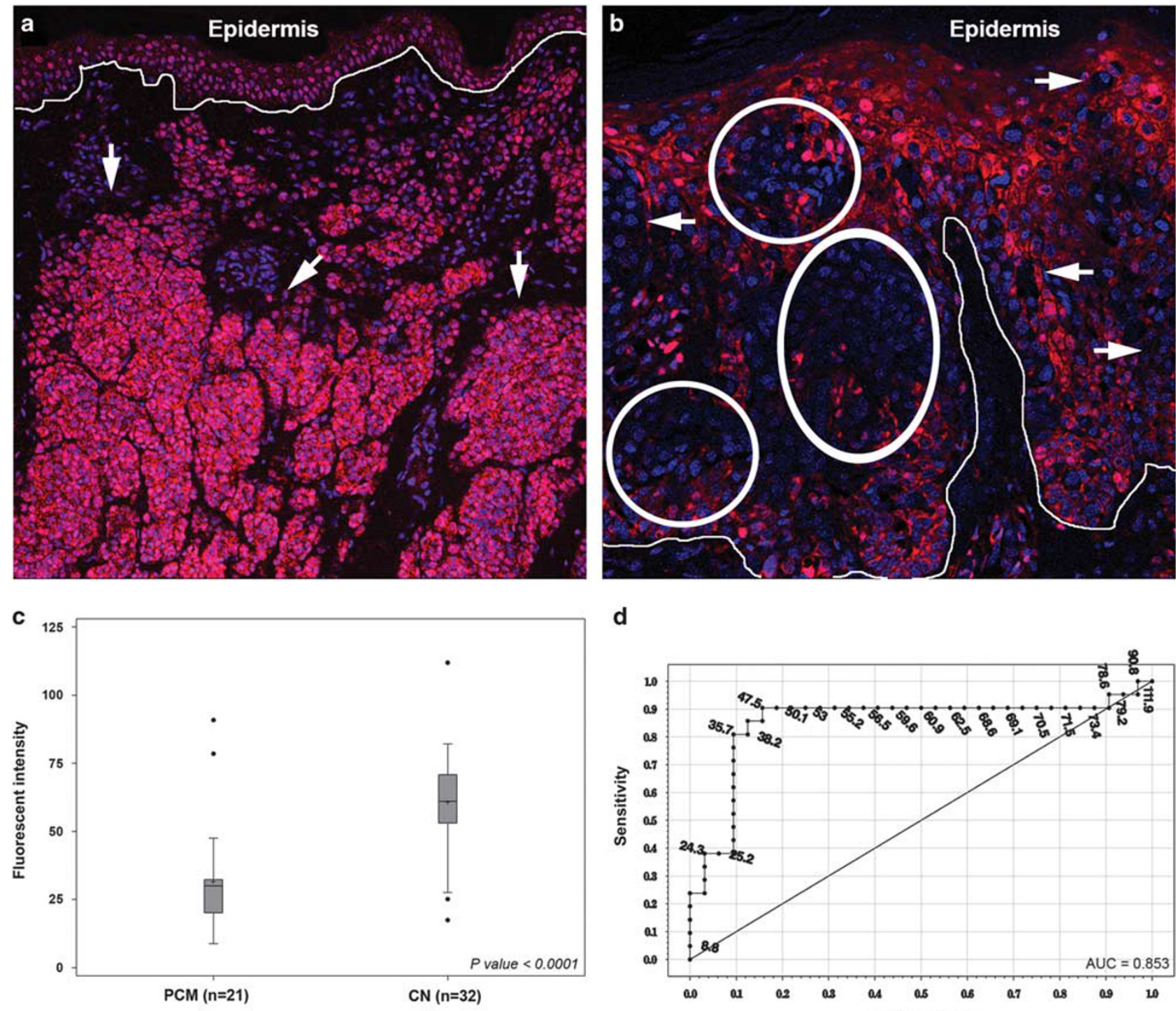

d

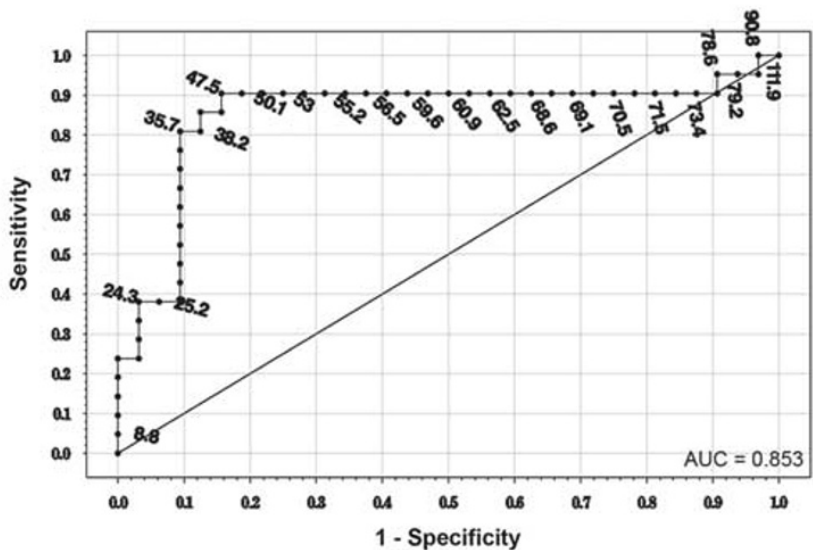

Figure 1 Intradermal nevus nests (arrows) and overlying epidermal keratinocytes diffusely and strongly express miR-211 (cytoplasm, red; and nuclei, blue) detected by fluorescent miRNA in situ hybridization (a). In contrast, the pagetoid, epidermal melanoma cells (circles and arrows) are negative for miR-211 (cytoplasm, black; and nuclei, blue) in a melanoma in situ (b). Measured fluorescent intensity showed a significant decrease in miR-211 expression in primary cutaneous melanomas compared with common nevi $(P$-value $<0.0001)(\mathbf{c})$. The fluorescent intensity was expressed in boxplots: box starts from first quartile and ends at third quartile; cross represents mean; line represents median; the ends of whiskers represent the minimum and maximum of the data that are not outliers; and black dots are outliers. Receiver operating characteristic curve showed an accurate discrimination between diagnostic primary cutaneous melanoma and common nevi groups (area under the curve $=0.853$ ) (d). Original magnifications: $(\mathbf{a}-\mathbf{b}), \times 200$.

specificity and then generated the receiver operator characteristic curve by plotting sensitivity vs (1 - specificity). From the receiver operator characteristic curve, AUC and the distance from ideal were calculated using previously described. ${ }^{17}$ The decision tree analysis to discriminate benign vs malignant outcome employed Classification and Regression Tree software (Salford Systems, San Diego, CA, USA). Using 10-fold cross-validation, the predictors included miRNA in situ hybridization intensity, sex, age and location.

\section{Results}

Significant Reduction of miR-211 Expression in Melanomas Compared with Common and Dysplastic Nevi

The study encompassed melanocytic tumors with a wide histopathological range from unequivocal common $(n=32)$ and dysplastic $(n=21)$ melanocytic nevi and primary cutaneous melanoma $(n=21)$ to more challenging lesions with Spitz morphology (Table 1). These cases included Spitz nevi $(n=11)$, 

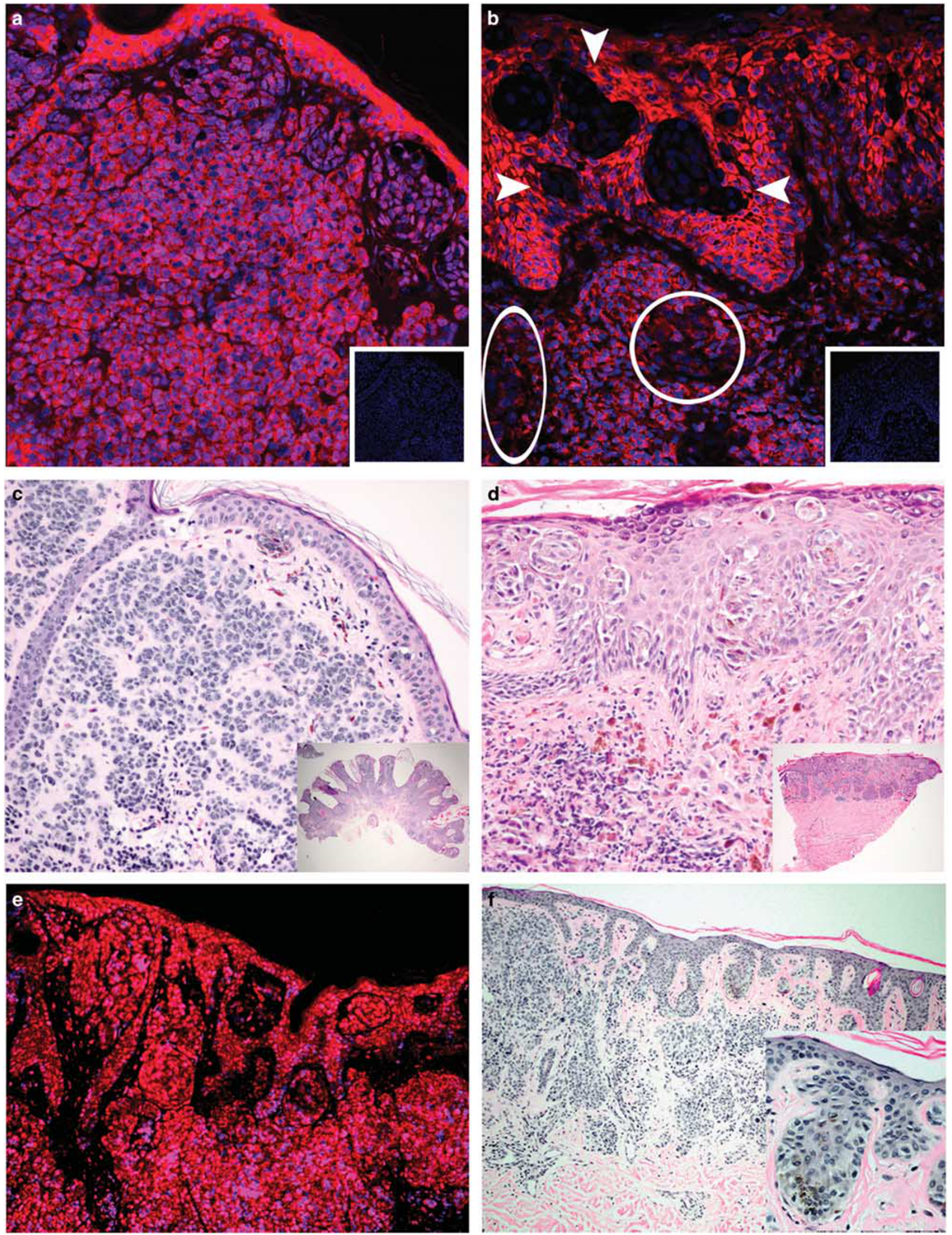
atypical Spitz tumors $(n=17)$ and spitzoid melanomas $(n=7)$. To examine the diagnostic utility of miR-211 in a total of 109 cases, we optimized an established methodology ${ }^{16}$ for miRNA in situ hybridization in paraffin-embedded specimen. The fluorescent intensity of miR-211 expression was measured for all lesions (Table 2), except for dysplastic nevi (Table 3). Given the small size of dysplastic nevi, mostly consisting of small, shave biopsies, miR-211 expression was scored in a semiquantitative manner, as fluorescent intensity could not be reproducibly measured with confidence using 3-5 overlapping fields.

The expression of miR-211 was consistently high and readily detected by fluorescent microscopy in all common and dysplastic nevi (Tables 1 and 2). miR-211 was diffusely and strongly expressed in the dermal nevus nests and the overlying epidermal keratinocytes; the signal was detected in the nuclei and cytoplasm (Figure 1a). In contrast, miR-211 was absent to dramatically decreased in 19 of the 21 melanomas (90\%) except for 2 cases that showed focal but modest expression of miR-211. miR-211 was consistently reduced to absent from the epidermal melanoma cells compared with the neighboring keratinocytes (Figure 1b). Combined immunofluorescent for MART-1 and miRNA in situ hybridization for miR-211 co-localized expression to intradermal nevus cells (results not shown). Although there was a range for miRNA in situ hybridization intensity, the mean and median values were significantly lower for melanomas compared with nevi, using two different statistical methods, showing consistent results $(P<0.0001$, Figure 1c). Receiver operating characteristic curve for miR-211 based on miRNA in situ hybridization intensity accurately discriminated melanomas from nevi (AUC $=0.853$, Figure 1d). Based on the receiver operating characteristic curve, the minimum distance from ideal of 0.17 was calculated, with sensitivity of $90 \%$, specificity of $86.2 \%$ and a false-positive rate of 0.138 .

To ensure the specificity of miR-211 signal, we used a scrambled miRNA (miRNA with non-specific sequence) as negative control, which showed no background or non-specific hybridization (Figures 2a and $\mathrm{b}$, insets). In contrast, diffusely strong and specific signal for miR-211 was detected in the nuclei and cytoplasm of intradermal nevus cells and overlying keratinocytes (Figure 2a). This signal was lost in the intraepidermal pagetoid melanoma cells, compared with the adjacent keratinocytes, and in the dermal melanoma cells compared with the adjacent intradermal nevus cells (Figure 2b). To ensure the integrity of small RNAs (including miRNAs) in archived paraffin material, we used U6 (a non-coding small nuclear RNA) as positive control (results not shown), virtually all the nuclei of epidermal keratinocytes and nevus cells highly expressed U6, indicating that small RNAs are intact in archived specimen. We observed a similar pattern of U6 expression in melanoma specimens (results not shown).

Similar to common nevi, the great majority of dysplastic lesions (18 of 21, 86\%) expressed miR-211 at high levels; the remainder (3 of 21, 14\%) expressed it at lower but detectable levels (Table 3). miR-211 expression was robust and diffuse in both the epidermal and dermal components of dysplastic nevi regardless of the degree of cytological atypia (Figures 2e and f). To demonstrate the reproducibility of miR-211 miRNA in situ hybridization, additional nevi were qualitatively compared with melanomas (Figure 3). Low-power examination showed a diffusely strong expression of miR-211 in the nuclei and cytoplasm of nevus cells (Figure 3a), absent from blood vessels (results not shown). A variable but detectable expression of miR-211 was demonstrated in the keratinocytes of epidermis and follicular epithelium (results not shown). In contrast, miR-211 expression was markedly reduced to absent in melanoma cells. In fact, the intraepidermal cells typically exhibited complete loss of miR-211 expression and left a negative imprint compared with the adjacent keratinocytes. However, in some cases the intradermal melanoma cells still expressed miR-211 (Figure 3b). Examining the relationship between miRNA in situ hybridization intensity and melanoma clinicopathological and American Joint Committee on Cancer parameters, such as Breslow's thickness, ulceration or mitotic index, revealed no significant association (Table 4). In addition, miRNA in situ hybridization intensity did not correlate with gender, age or solar elastosis, indicating that miRNA in situ hybridization could be used in a wide array of melanocytic tumors.

\section{Chromogenic miRNA In Situ Hybridization Distinguished Invasive Melanoma from Intradermal Nevus Cells in the Same Section}

We used fluorescent miR-211 miRNA in situ hybridization for its sensitivity in detection and quantification for all 109 tumors. After demonstrating the

Figure 2 Coalescing intradermal nevus nests diffusely expressed miR-211 (cytoplasm, red; and nuclei, blue) (a) compared with melanoma in situ (arrowheads) and invasive dermal (circles) tumor cells are negative for miR-211 (cytoplasm, black; and nuclei, blue) (b). The insets show negative control (miRNA scramble), devoid of any background or non-specific signal (cytoplasm, black; and nuclei, blue). Serial sections (hematoxylin and eosin) are shown for the two lesions in panels (a) and (b), respectively (c and d). Melanin did not interfere with the miR-211 hybridization or signal detection (d). Dysplastic nevi diffusely expressed miR-211 both in the junctional and dermal components (e). Serial section is shown (case no. 20) from the scalp of a 26 -year-old woman (f); the inset shows high magnification of the junctional melanocytic atypia. Original magnifications: (a-d), $\times 200$; and $(\mathbf{e})$ and $(\mathbf{f}), \times 100$. 

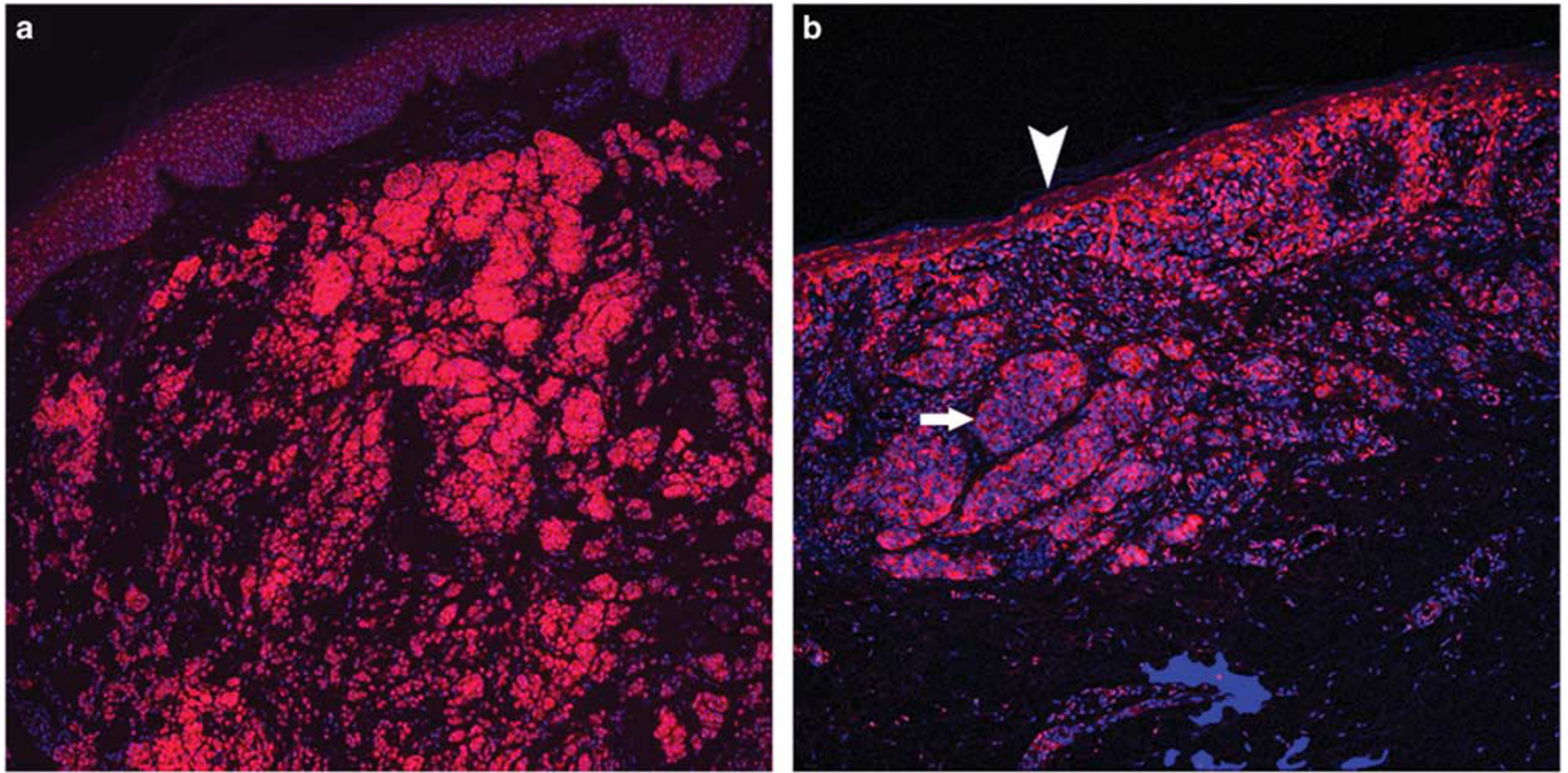

Figure 3 A reproducible, evenly diffuse expression of miR-211 (red) is detected in intradermal nevus nests (a) compared with a striking partial loss of miR-211 (cytoplasm, black; and nuclei, blue) in the situ (arrowhead) and invasive melanoma cells (arrow) (b). Original magnifications: (a-b), $\times 100$

Table 4 Clinicopathological correlation between fluorescent miR-211 intensity and melanoma American Joint Committee on Cancer parameters

\begin{tabular}{|c|c|c|c|c|c|}
\hline Parameter & $\mathrm{n}$ & miR-211 intensity, mean \pm s.d. & Median & Interquartile range & P-value ${ }^{\mathrm{a}}$ \\
\hline \multicolumn{6}{|l|}{ Gender } \\
\hline Female & 12 & $35.5 \pm 15.8$ & 31.6 & 10.2 & \multirow[t]{2}{*}{0.04 (non-parametric)/0.33 ( $t$-test) } \\
\hline Male & 9 & $26.5 \pm 25.5$ & 20.1 & 17.6 & \\
\hline \multicolumn{6}{|l|}{ Age, years } \\
\hline$<60$ & 8 & $23.8 \pm 9.1$ & 26.9 & 14.8 & \multirow{2}{*}{0.21} \\
\hline$\geq 60$ & 13 & $36.5 \pm 24.1$ & 30.8 & 21.8 & \\
\hline \multicolumn{6}{|c|}{ Pathological stage } \\
\hline I & 4 & $32.7 \pm 11.2$ & 31.4 & 14.5 & \multirow[t]{2}{*}{0.52} \\
\hline II, IIA, IIB, III & 15 & $32.7 \pm 23.2$ & 29.5 & 20.6 & \\
\hline \multicolumn{6}{|l|}{ Ulceration } \\
\hline Absent & 5 & $32.6 \pm 9.7$ & 32.3 & 1.8 & \multirow{2}{*}{0.40} \\
\hline Present & 5 & $37.4 \pm 30.6$ & 30.1 & 10.7 & \\
\hline \multicolumn{6}{|c|}{ Breslow's thickness } \\
\hline$<1.0$ & 4 & $32.7 \pm 11.2$ & 31.4 & 14.5 & \multirow[t]{2}{*}{0.75} \\
\hline$\geq 1.0$ & 6 & $36.5 \pm 27.5$ & 30.4 & 12.2 & \\
\hline \multicolumn{6}{|l|}{ Clark's level } \\
\hline III & 6 & $39.4 \pm 27.6$ & 31.4 & 27.2 & \multirow{2}{*}{0.75} \\
\hline IV/IV & 4 & $28.3 \pm 5.5$ & 30.4 & 6.4 & \\
\hline \multicolumn{6}{|c|}{ Mitotic index $\left(/ \mathrm{mm}^{2}\right)$} \\
\hline 0,1 & 3 & $36.8 \pm 9.3$ & 32.3 & 17.0 & \multirow[t]{2}{*}{0.36} \\
\hline$\geq 3$ & 7 & $34.2 \pm 25.8$ & 30.1 & 12.2 & \\
\hline \multicolumn{6}{|l|}{ Solar elastosis } \\
\hline Absent & 4 & $28.3 \pm 5.4$ & 30.3 & 6.2 & \multirow[t]{2}{*}{0.59} \\
\hline Present & 6 & $39.4 \pm 35.0$ & 27.6 & 31.6 & \\
\hline
\end{tabular}

aExcept for 'Gender', $P$-values shown here from non-parametric two-sample test (Mann-Whitney test) and two-sample $t$-test (not shown) are consistent. $P<0.05$ was considered statistically significant. 

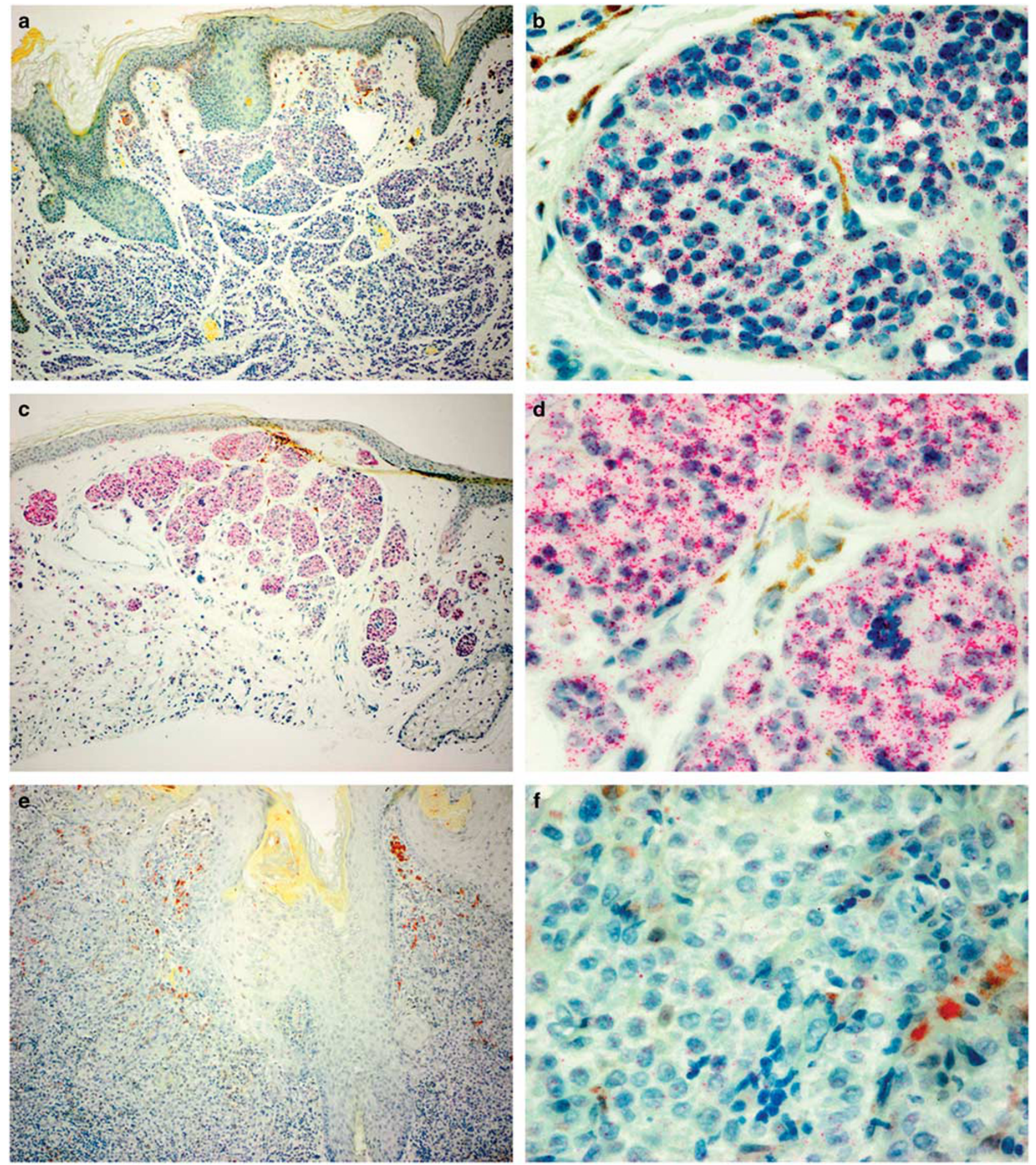

Figure 4 Chromogenic miRNA in situ hybridization using branched DNA probe also confirmed diffuse miR-211 expression in the nevus nests (red cytoplasmic grains) (a and b). Similarly, the nevic component (c and $\mathbf{d}$ ) in an invasive melanoma strongly expressed miR-211. In contrast, miR-211 expression was entirely lost in the melanoma area (e and $\mathbf{f})$ of the same lesion. Original magnifications: (a, c) and (e), $\times 100$; and (b), (d) and (f), $\times 600$.

feasibility of miR-211 detection by fluorescent miRNA in situ hybridization, we sought to establish a chromogenic probe so that it could be readily and conveniently detected by light microscopy. Using the well-established branched DNA probe chemistry, we detected diffuse expression of miR-211 in intradermal nevus nests (Figures 4a and b). In a case of melanoma associated with common intradermal nevus, miR-211 was robustly expressed in the banalappearing nevus nests (Figures 4c and d). However, 

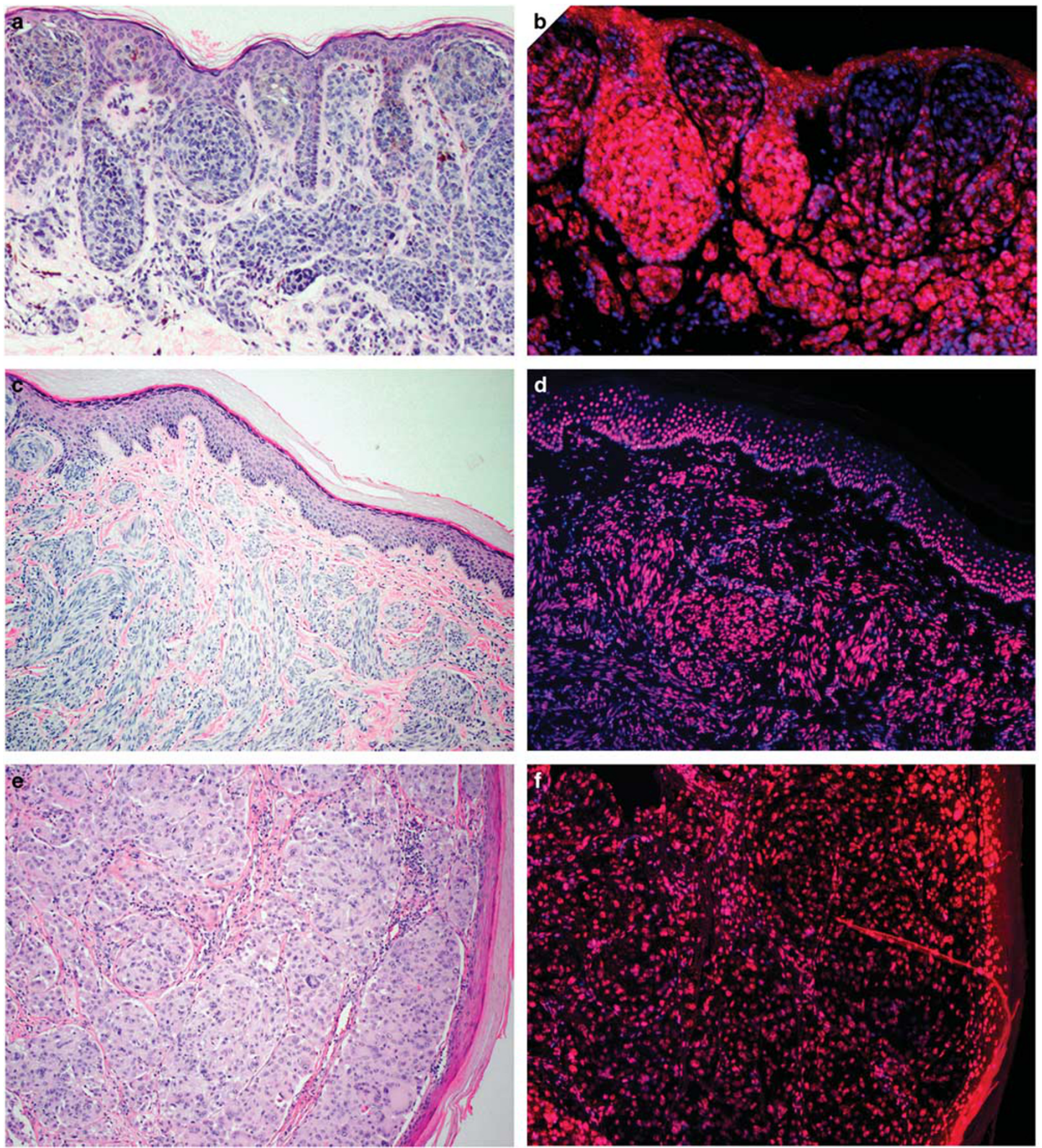

Figure 5 All melanocytic tumors with Spitz morphology expressed miR-211. Representative serial sections (hematoxylin and eosin) followed by fluorescent miRNA in situ hybridization are shown for Spitz nevus (a and b), atypical Spitz tumor (c and d) and spitzoid melanoma (e and f). The SM shown in panel (f) (case no. 30) expressing miR-211 was diagnosed as 2.5 mm melanoma (T3a) on the right calf of a 2-year-old girl; she has had no recurrence or metastasis after 4 years. Kruskal-Wallis test confirmed no statistical difference in miR-211 expression between the diagnostic groups for all lesions tested (g). Original magnification: (a-f), $\times 100$.

a separate section on the same slide showed histologically unambiguous melanoma where miR-211 signal is nearly completely lost (Figures 4e and f). For positive control, we used let-7a, a most abundantly expressed miRNA, which was diffusely expressed in the nevus cells, epidermal and follicular keratinocytes (results not shown). In contrast, in melanoma cells the expression of let-7a albeit being decreased, it was still detected by light microscopy. For negative control, we used a probe sequence to $D a p B$ gene, which was nearly absent from all the cases tested (results not shown). 


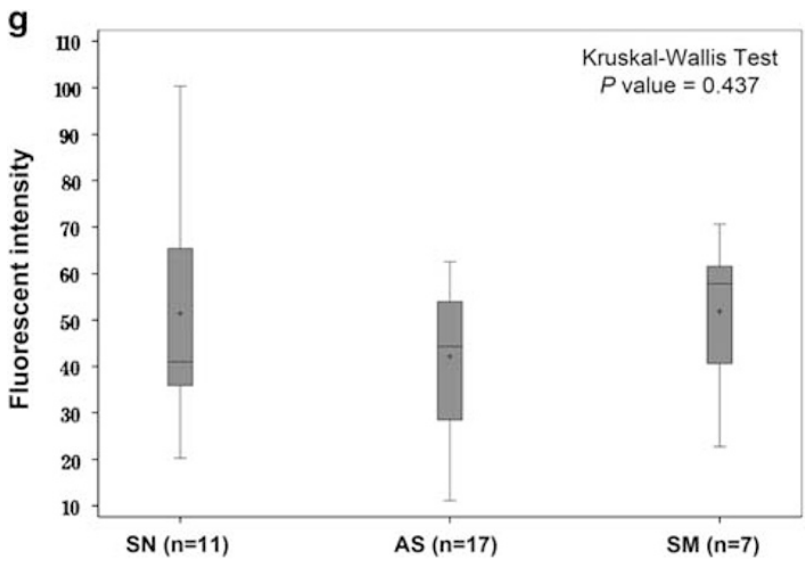

Figure 5 Continued.

\section{Melanocytic Tumors with Spitz Morphology Expressed miR-211}

Clinically, the Spitz nevus group was characterized by young age (mean age of 5.7 years) well defined and orange-to-pink papule or macule. The mean age of the patients diagnosed with atypical Spitz tumor and spitzoid melanoma was significantly higher than that of Spitz nevus (22.6 and 32.9 vs 5.7 years, respectively; Table 1). The median for miR-211 miRNA in situ hybridization intensity was near or above the melanoma threshold (47.5) in all 35 tumors with Spitz morphology (Table 2). Representative sections of Spitz nevus, atypical Spitz tumor and spitzoid melanoma showed diffuse expression of miR-211 (Figure 5). For example, a 2.5-mm melanoma (T3a) diagnosed on the right calf of a 2-year-old girl (case no. 30) diffusely expressed miR-211 (Figures 5e and f). She has had no recurrence or metastasis as determined by a negative PET scan after 4 years. Moreover, a 37-year-old man (case no. 32) diagnosed with spitzoid melanoma expressing miR-211 in the melanoma situ (Tis) with dermal nevus on the right ear has had no recurrence or metastasis after 2 years. A Kruskal-Wallis test for miR-211 expression confirmed no statistical difference between any of the diagnostic groups $(n=35$, Figure 5g). All atypical Spitz and spitzoid melanoma lesions were completely excised, and patients were followed for local recurrence by repigmentation in or near the scar, lymphadenopathy by palpation and PET scan as clinically indicated. The miR-211 expression results and follow-up results for each individual case are reported (Table 5). All 35 patients were followed up from 2 to 5 years with mean of 2.5, 3.4 and 3.0 years for Spitz nevus, atypical Spitz and SM lesions, respectively (Table 6); none of the lesions has recurred or metastasized to date. Moreover, miRNA in situ hybridization intensity did not correlate with gender, age, solar elastosis, Breslow's thickness, ulceration or mitotic index, regression or tumor-infiltrating lymphocytes response (results not shown).
miR-211 as Potential Marker of Clinical Behavior in Melanocytic Tumor

We applied classification and regression tree analysis as a predictive model to investigate which predictors could best classify the melanocytic tumors in our study. We used all lesions with available outcome results $(n=88)$; dysplastic nevi $(n=21)$ were excluded because of their semiquantitative miR-211 expression results. To obtain the best predictive model, a number of predictors such as sex, age, anatomic location, American Joint Committee on Cancer stage and miR-211 miRNA in situ hybridization intensity were explored. The classification and regression tree software selected age (younger vs $>48.5$ years) and miRNA in situ hybridization ( $\leq 48.8$, malignant; and $>48.8$, benign) intensity as the predictor variables for malignancy (Figure 6). The threshold for miRNA in situ hybridization intensity ( $\leq 48.8$, malignant; and $>48.8$, benign) is determined from classification and regression tree modeling analysis. This analysis accurately classified the great majority (96.5\%) of the patients aged $<48.5$ years as benign while $3.5 \%$ as malignant in node 1 . The remainder of 31 patients aged > 48.5 years could be accurately classified by miRNA in situ hybridization intensity threshold of 48.8 as benign or malignant in node 2 . In node 3 , only two lesions with high miRNA in situ hybridization intensity of 74.9 were misclassified as malignant. Overall, the receiver operating characteristic curve accurately discriminated between benign and malignant outcomes $(\mathrm{AUC}=0.9029)$.

\section{Discussion}

miRNAs are highly stable in paraffin-embedded tissues up to 10 years, ${ }^{18}$ and their expression levels can be reliably measured by qRT-PCR or sequencing. Therefore, the capability to qualitatively detect miRNA expression by light microscopy could have a significant impact in diagnostic pathology where 
Table 5 Clinicopathological characteristics of patients with melanocytic tumors with Spitz morphology, measured miR-211 fluorescent intensity and clinical follow-up

\begin{tabular}{|c|c|c|c|c|c|c|c|c|c|c|c|c|}
\hline $\begin{array}{l}\text { Case } \\
\text { no. }\end{array}$ & Groups & $\begin{array}{l}\text { miR-211 } \\
\text { intensity }\end{array}$ & Age & Sex & Site & $\begin{array}{l}\text { AJCC } \\
\text { stage }\end{array}$ & $\begin{array}{c}\text { Breslow's } \\
\text { depth (mm) }\end{array}$ & $\begin{array}{l}\text { Clark's } \\
\text { level }\end{array}$ & $\begin{array}{l}\text { Mitotic count } \\
\left(/ \mathrm{mm}^{2}\right)\end{array}$ & Metastasis & $\begin{array}{l}\text { Local } \\
\text { recurrence }\end{array}$ & $\begin{array}{c}\text { Follow-up } \\
\text { (years) }\end{array}$ \\
\hline 1 & Spitz nevus & 20.2 & 11 & $\mathrm{~F}$ & Finger & & & & & 0 & 0 & 3 \\
\hline 2 & Spitz nevus & 65.4 & 5 & M & Earlobe & & & & & 0 & 0 & 2 \\
\hline 3 & Spitz nevus & 55.9 & 1 & $\mathrm{~F}$ & Forearm & & & & & 0 & 0 & 2 \\
\hline 4 & Spitz nevus & 41.0 & 11 & $\mathrm{~F}$ & Back & & & & & 0 & 0 & 2 \\
\hline 5 & Spitz nevus & 37.1 & 6 & $\mathrm{M}$ & Nose & & & & & 0 & 0 & 2.5 \\
\hline 6 & Spitz nevus & 37.0 & 5 & $\mathrm{~F}$ & Cheek & & & & & 0 & 0 & 2.5 \\
\hline 7 & Spitz nevus & 100.3 & 1 & M & Calf & & & & & 0 & 0 & 4 \\
\hline 8 & Spitz nevus & 49.1 & 1.5 & & $\begin{array}{l}\text { Lower } \\
\text { eyelid }\end{array}$ & & & & & 0 & 0 & 2.5 \\
\hline 9 & Spitz nevus & 24.3 & 14 & M & Dorsal foot & & & & & 0 & 0 & 3 \\
\hline 10 & Spitz nevus & 99.4 & 7 & $\mathrm{~F}$ & Shoulder & & & & & 0 & 0 & 2 \\
\hline 11 & Spitz nevus & 35.9 & 1 & M & Dorsal foot & & & & & 0 & 0 & 2 \\
\hline 12 & $\begin{array}{l}\text { Atypical } \\
\text { Spitz tumor }\end{array}$ & 43.2 & 11 & $\mathrm{~F}$ & Upper arm & & & & & 0 & 0 & 3 \\
\hline 13 & $\begin{array}{l}\text { Atypical } \\
\text { Spitz tumor }\end{array}$ & 22.7 & 13 & $\mathrm{M}$ & Arm & & & & & 0 & 0 & 4 \\
\hline 14 & $\begin{array}{l}\text { Atypical } \\
\text { Spitz tumor }\end{array}$ & 54.6 & 4 & $\mathrm{~F}$ & Thigh & & & & & 0 & 0 & 5 \\
\hline 15 & $\begin{array}{l}\text { Atypical } \\
\text { Spitz tumor }\end{array}$ & 62.3 & 4 & M & Glabella & & & & & 0 & 0 & 5 \\
\hline 16 & $\begin{array}{l}\text { Atypical } \\
\text { Spitz tumor }\end{array}$ & 28.5 & 22 & $\mathrm{~F}$ & Back & & & & & 0 & 0 & 2 \\
\hline 17 & $\begin{array}{l}\text { Atypical } \\
\text { Spitz tumor }\end{array}$ & 57.5 & 12 & $\mathrm{~F}$ & Left cheek & & & & & 0 & 0 & 2 \\
\hline 18 & $\begin{array}{l}\text { Atypical } \\
\text { Spitz tumor }\end{array}$ & 44.3 & 32 & M & Upper arm & & & & & 0 & 0 & 4 \\
\hline 19 & $\begin{array}{l}\text { Atypical } \\
\text { Spitz tumor }\end{array}$ & 47.0 & 29 & $\mathrm{~F}$ & Thigh & & & & & 0 & 0 & 3 \\
\hline 20 & $\begin{array}{l}\text { Atypical } \\
\text { Spitz tumor }\end{array}$ & 11.1 & 35 & $\mathrm{~F}$ & Thigh & & & & & 0 & 0 & 3 \\
\hline 21 & $\begin{array}{l}\text { Atypical } \\
\text { Spitz tumor }\end{array}$ & 53.9 & 13 & $\mathrm{~F}$ & Foot & & & & & 0 & 0 & 3 \\
\hline 22 & $\begin{array}{l}\text { Atypical } \\
\text { Spitz tumor }\end{array}$ & 54 & 13 & $\mathrm{~F}$ & Foot & & & & & 0 & 0 & 3 \\
\hline 23 & $\begin{array}{l}\text { Atypical } \\
\text { Spitz tumor }\end{array}$ & 25.6 & 16 & $\mathrm{~F}$ & Chest & & & & & 0 & 0 & 3 \\
\hline 24 & $\begin{array}{l}\text { Atypical } \\
\text { Spitz tumor }\end{array}$ & 27.3 & 63 & M & Knee & & & & & 0 & 0 & \\
\hline 25 & $\begin{array}{l}\text { Atypical } \\
\text { Spitz tumor }\end{array}$ & 34.4 & 25 & $\mathrm{~F}$ & Hand & & & & & 0 & 0 & 3 \\
\hline 26 & $\begin{array}{l}\text { Atypical } \\
\text { Spitz tumor }\end{array}$ & 48.9 & 46 & $\mathrm{~F}$ & Thigh & & & & & 0 & 0 & 4 \\
\hline 27 & $\begin{array}{l}\text { Atypical } \\
\text { Spitz tumor }\end{array}$ & 62.5 & 33 & $\mathrm{~F}$ & $\begin{array}{l}\text { Right } \\
\text { upper arm }\end{array}$ & & & & & 0 & 0 & 5 \\
\hline 28 & $\begin{array}{l}\text { Atypical } \\
\text { Spitz tumor }\end{array}$ & 39.2 & 13 & $\mathrm{~F}$ & Left foot & & & & & 0 & 0 & 3 \\
\hline 29 & $\begin{array}{l}\text { Spitzoid } \\
\text { melanoma }\end{array}$ & 57.8 & 10 & M & Ear & T3aNoM0 & 1.9 & $\mathrm{~V}$ & 0 & 0 & 0 & 2 \\
\hline 30 & $\begin{array}{l}\text { Spitzoid } \\
\text { melanoma }\end{array}$ & 22.7 & 2 & $\mathrm{~F}$ & Right calf & T3aNoM0 & 2.5 & IV & 4 & 0 & 0 & 4 \\
\hline 31 & $\begin{array}{l}\text { Spitzoid } \\
\text { melanoma }\end{array}$ & 47.8 & 23 & M & Abdomen & T1aNoM0 & 0.55 & III & 0 & 0 & 0 & 4 \\
\hline 32 & $\begin{array}{l}\text { Spitzoid } \\
\text { melanoma }\end{array}$ & 61.6 & 37 & M & Right ear & TisNoMo & 0 & I & NA & 0 & 0 & 2.5 \\
\hline 33 & $\begin{array}{l}\text { Spitzoid } \\
\text { melanoma }\end{array}$ & 61.3 & 72 & $\mathrm{~F}$ & Buttock & T3aNoM0 & 3.5 & IV & 0 & 0 & 0 & 3 \\
\hline 34 & $\begin{array}{l}\text { Spitzoid } \\
\text { melanoma }\end{array}$ & 40.7 & 49 & $\mathrm{~F}$ & Right ear & TisNoMo & 0 & I & NA & 0 & 0 & 3 \\
\hline 35 & $\begin{array}{l}\text { Spitzoid } \\
\text { melanoma }\end{array}$ & 70.7 & 37 & $\mathrm{~F}$ & Thigh & T1bN0M0 & 0.72 & III & 2 & 0 & 0 & 4 \\
\hline
\end{tabular}

specific probes can be used to distinguish true cancer cells from normal counter parts with atypia or resolve a differential diagnosis of a tumor from its histological mimic. For example, using multi-color
miRNA in situ hybridization, higher expression of miR-205 could distinguish basal cell carcinoma from its histological mimic, Merkel cell carcinoma, and higher expression of miR-375 distinguished Merkel 
cell from basal cell carcinoma. ${ }^{19}$ Moreover, miRNA in situ hybridization can provide prognostic information using a single unstained section, eg, low

Table 6 Summary of clinical follow-up of patients with melanocytic tumors with Spitz morphology

Follow-up period (years)

\begin{tabular}{lccccc}
\hline Diagnostic group & $\mathrm{n}$ & Mean & Median & Minimum & Maximum \\
\hline Spitz nevus & 11 & 2.5 & 2.5 & 2.0 & 4.0 \\
Atypical Spitz & 17 & 3.4 & 3.0 & 3.0 & 5.0 \\
tumor & & 3.0 & 3.0 & 2.0 & 4.0 \\
Spitzoid melanoma & 7 & & & & \\
\hline
\end{tabular}

All group are recurrence free after the indicated follow-up period. levels of miR-205 expression showed a significantly shorter melanoma-specific survival. ${ }^{16}$

Our results showed that miR-211 miRNA in situ hybridization, independent of histology, could reliably classify melanoma from nevus groups in $90 \%$ (19 of 21) of lesions with the exception of two cases, where modest levels of miR-211 was detected. In addition, applying classification and regression tree analysis with patient's age at diagnosis and miRNA in situ hybridization intensity as parameters $97 \%$ of cases were correctly classified. Although these two cases would have been underdiagnosed, the histopathology was characteristic of melanoma. There is clearly a range of measured miR-211 expression, and some overlap between the lower end of nevus and higher end of melanoma groups. In

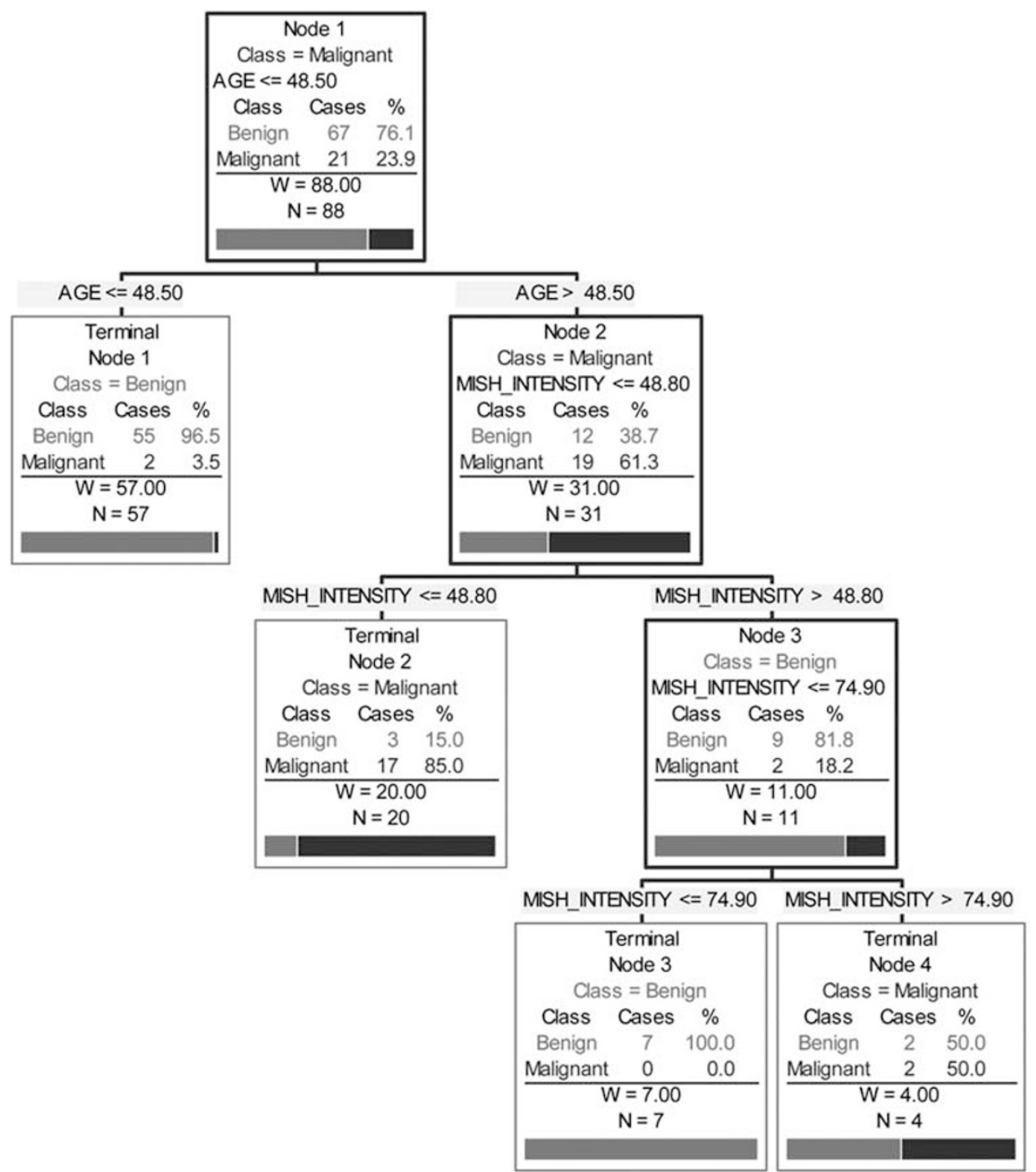

Figure 6 Using classification and regression tree analysis, the decision tree diagram is predicted for melanocytic tumors ( $n=88$ ) according to benign vs malignant outcome. The age and miRNA in situ hybridization intensity shaped the specific tree as shown (area under the curve $=0.9029$ ). In each node, the gray color represents benign and black represents malignant, highlighting the percentage of patients for each classification. The total number of patients is shown as ' $N$ '. 
such cases, we noted that measured fluorescence was a combination of partial, residual expression of miR-211 by melanoma cells and high expression by the adjacent keratinocytes, likely giving a falsely high readout. This situation will be avoided by using chromogenic miRNA in situ hybridization where the expression of miR-211is nevus specific, ie, not detected in the epidermal or follicular keratinocytes. Finally, we do not recommend the use of miR-211 miRNA in situ hybridization alone without a complete, thorough histological examination because miRNA in situ hybridization is an ancillary test. If the histopathology is dysplastic, spitzoid or ambiguous, then a miR-211 chromogenic miRNA in situ hybridization could be helpful in devising a more personalized treatment and clinical follow-up strategy for the patient.

miRNA in situ hybridization intensity in lesions with Spitz morphology retained miR-211 expression independent of morphological classification even in spitzoid melanomas, where clinical follow-up of all 35 patients showed no recurrence at the site or metastasis in mean and median of 3 (ranging 2-5) years. There are two possible explanations for retained miR-211 expression in such cases: (1) lesions with Spitz morphology were overdiagnosed because of cytological atypia and/or (2) the follow-up of the spitzoid melanomas was not long enough. The current, published literature supports the fact that many patients with spitzoid melanocytic tumor have a favorable clinical outcome. Based on this, miRNA in situ hybridization could significantly relieve the stress of unambiguity of atypical Spitz tumors, where a simple excision with 5-mm clear peripheral margins would be curative. It is possible that our follow-up of 3 years (ranging from 2 to 4 years) may not be long enough in a 2- or a 10-year-old child (cases SM29 and SM30); however, a 3-year follow-up is more than adequate for older individuals ranging from 23 to 72 (cases SM 31-35). Interestingly, miR-211 expression did not correlate with any of the American Joint Committee on Cancer prognostic parameters (especially tumor thickness, ulceration or mitotic index) or tumoral melanosis, suggesting that miR-211 miRNA in situ hybridization could have a broader diagnostic utility in melanocytic pathology regardless of the tumor stage or melanin content.

Using a chromogenic probe with branched DNA can significantly improve specificity because of the proven, powerful design of the nucleic acid chemistry. ${ }^{20}$ Chromogenic miRNA in situ hybridization provides additional advantages: (1) melanoma can be distinguished from nevus cells on the same tumor section; (2) miR-211 expression was specific to the nevus cells; (3) the results are readily interpreted by the pathologist using light microscopy; and (4) miRNA in situ hybridization is less expensive than DNA-based fluorescent in situ hybridization or comparative genomic hybridization and widely available to pathology laboratories. Overall, the current results combined with sequencing and
qRT-PCR support miR-211 as a leading miRNA candidate for melanoma diagnosis and miRNA in situ hybridization as a uniquely uncomplicated ancillary test.

\section{Acknowledgments}

We thank Ms Elizabeth Fleming for excellent technical assistance and Mrs Tamara Thorpe, HT, for assistance with histology.

\section{Disclosure/conflict of interest}

The authors declare no conflict of interest.

\section{References}

1 Howlader NNA, Krapcho M, Neyman N, et al. (eds). SEER Stat Fact Sheets: Skin (excl. Basal and Squamous). In: SEER Cancer Statistics Review, 1975-2009 (Vintage 2009 Populations), 2012 edn. National Cancer Institute: Bethesda, MD, USA, 2012. Posted to the SEER web site, http://seer.gov.cancer/csr/1975_2009_pops09/results_single/ sect_01_table.01.pdf.

2 McGinnis KS, Lessin SR, Elder DE et al. Pathology review of cases presenting to a multidisciplinary pigmented lesion clinic. Arch Dermatol 2002;138: 617-621.

3 Cerroni L, Barnhill R, Elder D et al. Melanocytic tumors of uncertain malignant potential: results of a tutorial held at the XXIX Symposium of the International Society of Dermatopathology in Graz, October 2008. Am J Surg Pathol 2010;34:314-326.

4 Curtin JA, Fridlyand J, Kageshita T et al. Distinct sets of genetic alterations in melanoma. $\mathrm{N}$ Engl J Med 2005;353:2135-2147.

5 Gerami P, Jewell SS, Morrison LE et al. Fluorescence in situ hybridization (FISH) as an ancillary diagnostic tool in the diagnosis of melanoma. Am J Surg Pathol 2009;33:1146-1156.

6 Bartel DP, Chen CZ. Micromanagers of gene expression: the potentially widespread influence of metazoan microRNAs. Nat Rev Genet 2004;5:396-400.

7 Esquela-Kerscher A, Slack FJ. Oncomirs - microRNAs with a role in cancer. Nat Rev Cancer 2006;6:259-269.

8 Ryan BM, Robles AI, Harris CC. Genetic variation in microRNA networks: the implications for cancer research. Nat Rev Cancer 2010;10:389-402.

9 Lu J, Getz G, Miska EA et al. MicroRNA expression profiles classify human cancers. Nature 2005;435: 834-838.

10 Kozubek J, Ma Z, Fleming E et al. In-depth characterization of microRNA transcriptome in melanoma. PLoS One 2013;8:e72699.

11 Levy C, Khaled M, Iliopoulos D et al. Intronic miR-211 assumes the tumor suppressive function of its host gene in melanoma. Mol Cell 2010;40:841-849.

12 Mazar J, DeYoung K, Khaitan D et al. The regulation of miRNA-211 expression and its role in melanoma cell invasiveness. PLoS One 2010;5:e13779.

13 Babapoor S, Fleming E, Wu R et al. A novel miR-451a isomiR, associated with amelanotypic phenotype, acts 
as a tumor suppressor in melanoma by retarding cell migration and invasion. PLoS One 2014;9:e107502.

14 Duncan LM, Deeds J, Hunter J et al. Down-regulation of the novel gene melastatin correlates with potential for melanoma metastasis. Cancer Res 1998;58:1515-1520.

15 Duncan LM, Deeds J, Cronin FE et al. Melastatin expression and prognosis in cutaneous malignant melanoma. J Clin Oncol 2001;19:568-576.

16 Hanna JA, Hahn L, Agarwal S et al. In situ measurement of miR-205 in malignant melanoma tissue supports its role as a tumor suppressor microRNA. Lab Invest 2012;92:1390-1397.

17 Gerami P, Li G, Pouryazdanparast P et al. A highly specific and discriminatory FISH assay for distinguishing between benign and malignant melanocytic neoplasms. Am J Surg Pathol 2012;36:808-817.

18 Ma Z, Lui WO, Fire A et al. Profiling and discovery of novel miRNAs from formalin-fixed, paraffin-embedded melanoma and nodal specimens. J Mol Diagn 2009;11: 420-429.

19 Renwick N, Cekan P, Masry PA et al. Multicolor microRNA FISH effectively differentiates tumor types. J Clin Invest 2013;123:2694-2702.

20 Ferrone CR, Ting DT, Shahid M et al. Erratum to: the ability to diagnose intrahepatic cholangiocarcinoma definitively using novel branched DNA-enhanced albumin RNA in situ hybridization technology. Ann Surg Oncol 2015;3:1604. 